\title{
The Many Faces of Cytokine Release Syndrome-Related Coagulopathy
}

\author{
Jiasheng Wang*,(D), John Doran \\ Department of Internal Medicine, MetroHealth Medical Center, Case Western Reserve University, Cleveland, OH, USA
}

\section{ARTICLE INFO}

\section{Article History}

Received 14 November 2020

Accepted 10 January 2021

\section{Keywords}

Cytokine

Coagulopathy

CAR T cell

Hemophagocytic

lymphohistocytosis

COVID-19

\begin{abstract}
Cytokine release syndrome (CRS) has been increasingly recognized in various conditions including the coronavirus disease 2019 (COVID-19). It is not only associated with systemic inflammatory symptoms, but also hematological complications such as coagulopathy. CRS can affect various components of the coagulation pathway, including the endothelial cells, platelets, coagulation cascade, and fibrinolytic system. Different causes of CRS, such as primary hemophagocytic lymphohistocytosis (HLH), chimeric antigen receptor (CAR) T-cell therapy, and COVID-19, have different cytokine profiles and coagulopathy presentations, with microvascular thrombosis surfacing as a common pathology. HLH shares many features with severe CRS, and is characterized by severe consumptive coagulopathy, frequent disseminated intravascular coagulation and an increased bleeding risk. CAR T-cell therapy is characterized by frequent and mild consumptive coagulopathy, as well as an increased risk of thrombosis. While consumptive coagulopathy is rare in COVID-19, it is associated with an increased thrombotic risk. The differences can be explained by the severity of CRS and underlying conditions associated with coagulopathy. Various treatments, including cytokine inhibitors, plasma exchange, Janus kinases inhibitors, complement blockade, and corticosteroids are being studied to mitigate CRS-related coagulopathy.
\end{abstract}

(c) 2021 International Academy for Clinical Hematology. Publishing services by Atlantis Press International B.V. This is an open access article distributed under the CC BY-NC 4.0 license (http://creativecommons.org/licenses/by-nc/4.0/).

\section{INTRODUCTION}

Cytokine release syndrome (CRS), or cytokine storm, is an acute inflammatory syndrome caused by the activation of immune cells and release of proinflammatory cytokines. Starting as a fever, it can rapidly progress to hypotension, hypoxia, and end-organ dysfunction. Since the advent of chimeric antigen receptor (CAR) T-cell therapy, our understanding of the pathophysiology and treatment of CRS has greatly progressed. Initially described in patients receiving muromonab-CD3 [1], CRS is now commonly encountered in primary hemophagocytic lymphohistocytosis (HLH), bi-specific T-cell engager (BiTE) therapy, CAR T-cell therapy, haploidentical hematopoietic stem cell transplantation (haplo-HSCT) with post-transplantation cyclophosphamide (PTCy), as well as the coronavirus disease 19 (COVID-19) [2]. In addition to causing systemic inflammatory response, CRS is also linked to hematological toxicities such as coagulopathy.

The association between inflammation and thrombosis has been increasingly recognized in recent years. The term "thromboinflammation" was first used by Blair et al. [3] in 2009 to describe the activation of Toll-like receptors on platelets, leading to both inflammatory response and thrombosis. Since then, a growing body of literature supports the association between thrombosis and various inflammatory states - infection, autoimmune disorders, viperid snake envenomation, major trauma, and ischemia/reperfusion

"Corresponding author. Email: jxw1170@case.edu

Peer review under responsibility of the International Academy for Clinical Hematology injury. This review will focus on the different presentations of coagulopathy associated with three different conditions leading to a CRS: primary HLH, CAR T-cell therapy, and COVID-19. These three entities are, so far, the best studied. Here, we summarize the pathogenesis, presentations, as well as management of CRS-related coagulopathy.

\section{MECHANISTIC ASSOCIATION BETWEEN CRS AND COAGULATION}

Cytokine release syndrome is characterized by the elevation of various cytokines, most noticeably interleukin-6 (IL-6), IL-1, interferon-gamma (IFN- $\gamma$ ), and tumor necrosis factor alpha (TNF- $\alpha$ ). Other cytokines, including IL-8, IL-10, monocyte chemoattractant protein-1 (MCP-1), and granulocyte-macrophage colonystimulating factor (GM-CSF) are also consistently elevated [4]. The formation of thrombosis occurs in two steps - primary hemostasis which involves the crosstalk between the endothelial cells and platelets, and secondary hemostasis which involves the coagulation cascade. Different cytokines can affect different components of the thrombosis formation process, leading to a hypercoagulable state (Figure 1).

\subsection{Effects of Cytokines on Endothelial Cells}

The endothelium covers the lumen of the entire venous and arterial system. Resting endothelial cells (ECs) help maintain homeostasis by 

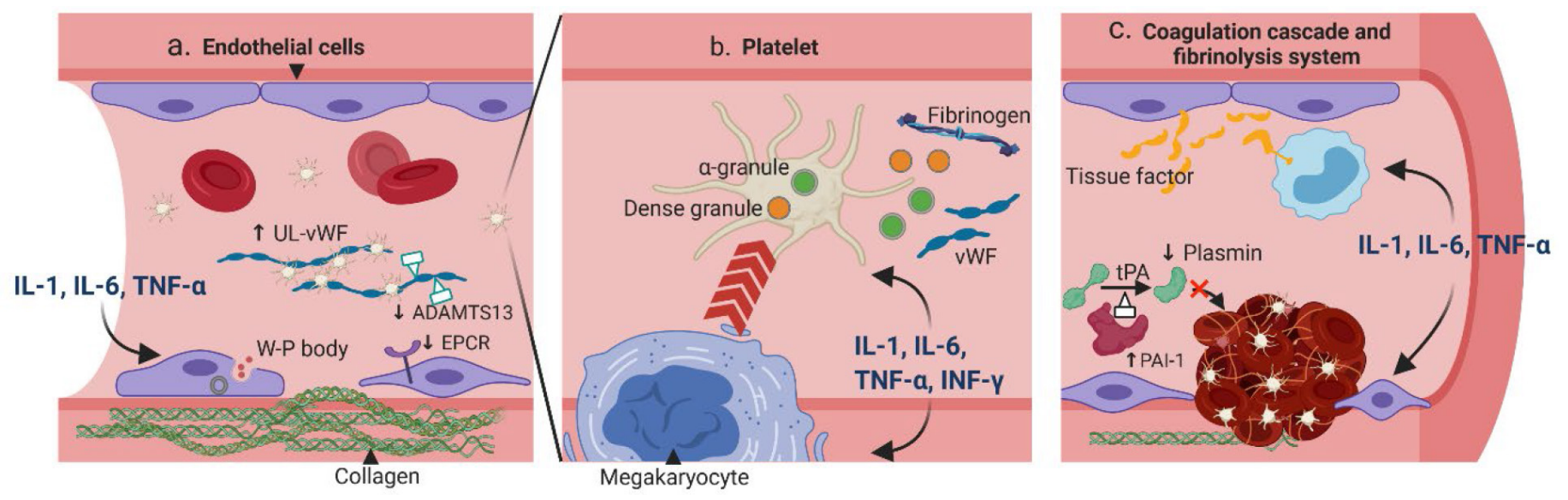

Figure 1 Pathogenesis of CRS-related coagulopathy. (a) Pro-inflammatory cytokines IL-1, IL-6 and TNF- $\alpha$ can stimulate endothelial cells (ECs) to secrete Weibel-Palade (W-P) body, which contains ultra-large von Willebrand factor (UL-vWF) and P-selection; both are essential for platelet attachment. Moreover, the cytoskeletons of ECs are rearranged to expose the procoagulant collagen. The expressions of anticoagulant proteins such as the endothelial protein C receptors (EPCR) and ADAMTS-13 are also downregulated. (b) Cytokines IL-1, IL-6, TNF- $\alpha$ and IFN- $\gamma$ can affect the quantity and quality of platelets. The megakaryocyte maturation is accelerated resulting in more platelets. These cytokines can also stimulate the release of dense granules and $\alpha$-granules, which contain essential coagulation substrates such as the fibrinogen and vWF. (c) Cytokines IL-1, IL-6, and TNF- $\alpha$ can increase the expression of tissue factor from ECs and on monocytes. In addition, the fibrinolytic system is inhibited with increased expression of plasminogen activator inhibitor type I (PAI-1), which can deactivate tPA and result in less plasmin. ADAMTS, a disintegrin and metalloproteinase with thrombospondin motifs; IFN, interferon; tPA, tissue plasminogen activator.

preventing platelet adhesion, decreasing inflammation, and releasing natural anticoagulants [5]. However, upon exposure to inflammatory stimuli, ECs can rapidly transform the surrounding environment into a procoagulant state, through exocytosis of procoagulant particles, breakdown of the endothelial barrier, and down-regulation of the anticoagulant pathways [6]. This process, also known as the type II endothelial activation or delayed sustained activation, is the initial step of inflammation-related coagulation [7]. More specifically, cytokines such as IL-1, IL- 6 and TNF- $\alpha$ can activate the MAPK/ NF- $\kappa B$ pathway within the ECs, leading to synthesis and release of procoagulant particles such as the Weibel-Palade bodies [8-10]. The particles contain ultra-large von Willebrand factor (vWF) and P-selectin, which can together form a network with other coagulant factors, platelets and inflammatory cells. In addition, the signaling pathway activation can also lead to reorganization of the ECs' cytoskeleton [11] and loss of tight junctions [12], resulting in exposure of the highly coagulant collagen. Moreover, the natural anticoagulant pathways are inhibited when cytokines are present, through mechanisms such as decreased expression of endothelial protein $\mathrm{C}$ receptors [13] or inhibited synthesis of a disintegrin and metalloproteinase with thrombospondin motifs 13 (ADAMTS-13) [14].

\subsection{Effects of Cytokines on Platelets}

Platelets not only serve as building blocks of the hemostatic plug, but also act as gatekeepers of the vascular wall to help preserve vascular integrity during inflammation in a non-aggregated form. Cytokines can affect platelets both quantitatively and qualitatively. In vitro studies found that IL- 6 can promote the maturation of megakaryocytes [15], and injection of IL-6 in humans was associated with an increased platelet count [16]. On the other hand, IL-1 administration can not only promote megakaryocyte differentiation, but also induce its rupture, leading to immediate release of platelets into the circulation [17]. Other cytokines, such as the TNF- $\alpha$ and IFN- $\gamma$, have also been shown to increase the platelet production [18]. Moreover, cytokines can regulate the secretion of platelet granules. The dense granules of platelets are filled with small molecules such as adenosine diphosphate (ADP), calcium, and polyphosphate (polyP), whereas the $\alpha$-granules contain coagulation factors such as the vWF, fibrinogen (factor I), factor V, XI and XIII [19]. Both granules contribute to the platelet aggregation and the coagulation cascade. Upon inflammation, IFN- $\gamma$ and IL-1 can enhance platelet dense granule secretion [20], while IL-2 can attenuate $\alpha$-granules secretion [21]. In addition, activated platelets can reversely interact with immune cells - through direct contact or soluble mediators - and lead to further elevation of cytokines [22].

\subsection{Effects of Cytokines on the Coagulation Cascade}

Tissue factor (TF) is the initiator for the extrinsic coagulation cascade and is expressed on a variety of cells at different levels. IL-6 and TNF- $\alpha$ have been shown to stimulate the secretion of a soluble and highly procoagulant isoform of TF from ECs [23]. Moreover, IL- 1 and TNF- $\alpha$ can rapidly upregulate TF expression on circulating monocytes, which comprise a large pool of TF [24]. Conversely, the TF-Factor VIIa complex can couple with protease-activated receptors (PARs) to induce cytokine release from the immune cells and ECs, further fueling the CRS [25]. On the other hand, thrombin is involved in the terminal steps of the coagulation cascade and plays a central role in thrombosis propagation. A human study showed that a single bolus of TNF- $\alpha$ was able to induce a rapid conversion from prothrombin to thrombin [26].

In addition to promoting the coagulation cascade, cytokines can also suppress anticoagulant mechanisms. The thrombomodulin/ 
protein $\mathrm{C} /$ protein $\mathrm{S}$ pathway, an important mechanism to prevent excessive fibrin deposition, can be suppressed by IL-1 and TNF- $\alpha$. Both cytokines downregulate thrombomodulin activity [27], as well as decrease protein $\mathrm{C}$ activity by reducing endothelial protein $\mathrm{C}$ receptor (EPCR) expression or stimulating its exocytosis $[13,28]$.

\subsection{Effects of Cytokines on the Fibrinolytic System}

Fibrinolysis is mediated by plasmin, an enzyme converted from plasminogen by tissue plasminogen activators and urokinase plasminogen activators (tPA and uPA). A delicate balance between the coagulation and fibrinolytic system maintains the homeostasis of vasculature. Cytokines exerting anti-fibrinolytic effects can tilt the system toward a procoagulant state. In vitro, IL-1, TNF- $\alpha$, and IFN- $\gamma$ can stimulate ECs to produce plasminogen activator inhibitor type I (PAI-1), the main inhibitor of tPA, resulting in less plasmin production $[29,30]$. Interestingly, the secretions of $\mathrm{PA}$ and $\mathrm{PAA}$ are also parallelly increased with IL- 1 and TNF- $\alpha[31,32]$, although the majority of the secreted form have low affinity to plasmin [32]. Studies in healthy volunteers provide more direct evidence of cytokines affecting the fibrinolytic system. Administration of inhibitory cytokine IL-10 inhibits activation of the fibrinolytic system during induced endotoxemia [33]. On the other hand, administration of TNF- $\alpha$ was associated with a transient activation of the fibrinolytic system due to increased secretion of tPA and uPA, followed by a rapid inhibition thereafter, consistent with in vitro results [34].

\section{PRESENTATIONS OF CRS-RELATED COAGULOPATHY}

Cytokine release syndrome is commonly recognized in primary HLH [35], BiTE therapy [36], CAR T-cell therapy [37], PTCybased haplo-HSCT [38,39], and various infections, including the severe acute respiratory syndrome (SARS) [40], Middle East respiratory syndrome (MERS) [41], and COVID-19 [2]. However, presentations of coagulopathy differ among different underlying conditions. In this section, presentations of CRS-related coagulopathy in the three best studied scenarios, HLH, CAR T-cell therapy, and COVID-19, are summarized. The pathogenesis of CRS in the three conditions is summarized in Figure 2.

\subsection{Coagulopathy in HLH}

Hemophagocytic lymphohistocytosis is a syndrome of fulminant inflammation and tissue destruction caused by unregulated activation of macrophages. Being either familial or secondary to inflammatory conditions, it is characterized by macrophages engulfing different components of blood cells with excessive production of cytokines. Familial or primary HLH is a congenital immune deficiency due to genetic mutations affecting granule-mediated cytotoxicity in natural killers (NK) cells or cytotoxic lymphocytes (CTLs) [42] (Figure 2a). On the other hand, secondary HLH is associated with a variety of inflammatory conditions, such as rheumatologic disorders, malignancies and infection, although the exact
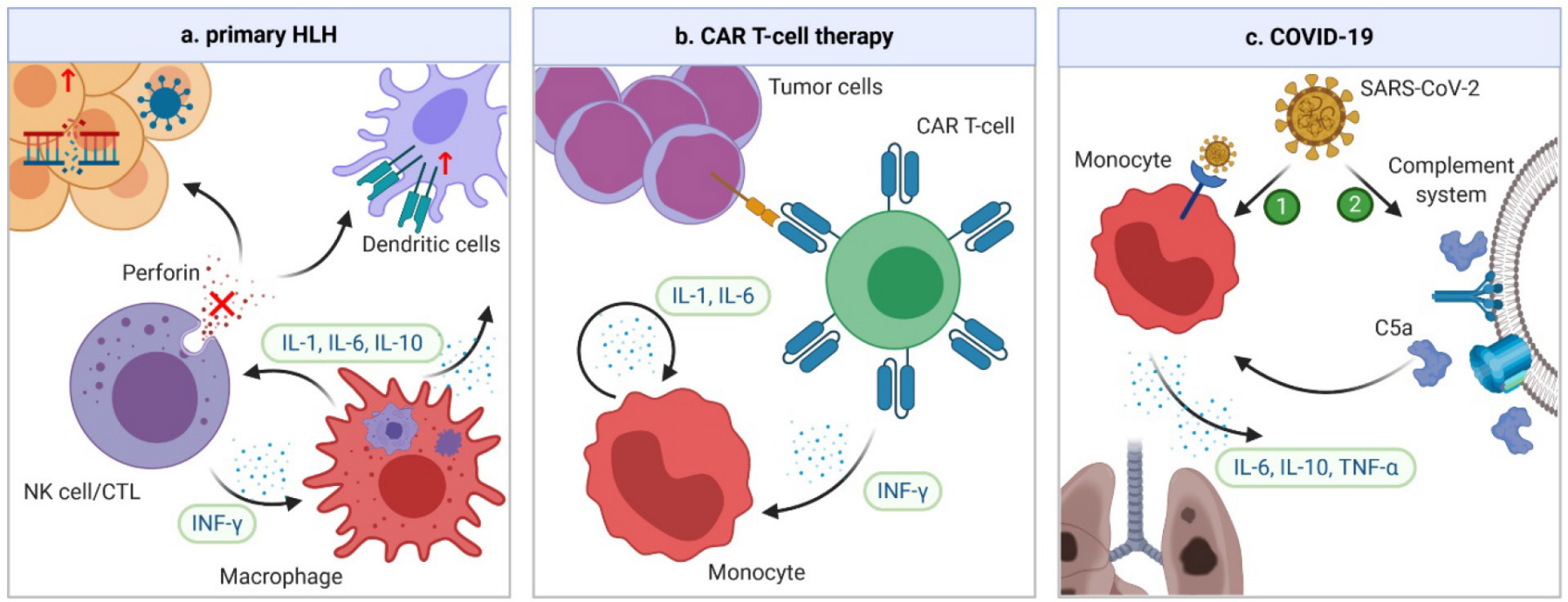

Figure 2 Mechanisms of CRS in HLH, CAR-T cell therapy, and COVID-19. (a) In familial HLH, defects of granule-mediated cytotoxicity (e.g. perforin) in natural killers (NK) cells or cytotoxic lymphocytes (CTLs) lead to impaired killing of diseased human cells. When a trigger, such as a viral infection or genetic mutation occurs, the heightened antigen exposure results in activation of dendritic cells (DCs), whose elimination is further impaired due to defective NK/CTLs. DCs subsequently activate more NK/CTLs, leading to secretion of IFN- $\gamma$ and activation of macrophages. In turn, macrophages secrete more pro-inflammatory cytokines, leading to a vicious cycle. (b) In CAR T-cell therapy, the CRS is the result of the interplay between CAR T-cells and bystander immune cells. When CAR T-cell and tumor cells are engaged, CAR T-cells are activated and start secreting IFN- $\gamma$, which can attract and activate the monocytes. Activated monocytes can secrete key CRS cytokines IL-1 and IL-6, which forms a vicious cycle by activating more monocytes. (c) The pathogenesis of CRS in COVID-19 is unclear. However, it could be secondary to direct infection and activation of immune cells through ACE- 2 receptors by severe acute respiratory syndrome coronavirus 2 (SARS-CoV-2). Another possibility is that the complement system can be activated by SARS-CoV-2 infection, which triggers formation of $\mathrm{C} 5 \mathrm{a}$ anaphylatoxin. The latter can directly activate neutrophils and monocytes, causing CRS. ACE, angiotensinconverting enzyme. 
mechanisms of secondary HLH remain unclear. Accumulating evidence has suggested a significant overlap between HLH and severe CRS in terms of laboratory findings, cytokine profiles, and clinical presentations $[43,44]$. In fact, HLH can have the same underlying pathophysiology as severe CRS [44]. The diagnosis of HLH is based on eight criteria: fever, splenomegaly, cytopenia in at least two cell lines, hypertriglyceridemia and/or hypofibrinogenemia, hemophagocytosis, low or absent NK cell activity, hyperferritinemia, and high soluble IL-2 receptor levels. Indeed, these findings are also commonly encountered in severe CRS. The cytokine profile varies slightly with different etiologies of HLH [45], but levels of IFN- $\gamma$, IL-6, and IL-10 are universally elevated [35,46,47]. Among them, IFN- $\gamma$ plays a central role [48]. Coagulopathy is common in patients with HLH. Laboratory findings are consistent with severe consumptive coagulopathy. For example, in a series of 117 patients with HLH due to mixed causes, all patients had thrombocytopenia, $41 \%$ had prothrombin time (PT) less than $50 \%$ of the normal value, $68 \%$ had hypofibrinogenemia, and $50 \%$ had disseminated intravascular coagulation (DIC) [49]. In another series of 23 patients with therapy-refractory HLH, 16 (69.6\%) had clinical signs of thrombotic microangiopathy (TMA) [50]. Clinically, the coagulopathy predominantly manifests as bleeding, likely due to severe thrombocytopenia and DIC [51]. In a study of critically ill patients with HLH, 22\% suffered from severe bleeding and $4.3 \%$ died from serious bleeding complications [49].

\subsection{Coagulopathy in Anti-CD19 CAR T-cell Therapy}

Chimeric antigen receptors are engineered receptors consisting of an ectodomain that can recognize tumor antigen, and an endodomain that can transmit the signal to activate T-cells [52]. Anti-CD19 CAR T-cell therapy has revolutionized the treatment of relapsed/refractory B-cell malignancies with unprecedented durable remissions. CRS, the most common serious adverse effect of CAR T-cell therapy, occurs in about one-half of the patients, and 10-20\% experience severe CRS [53,54]. Triggered by activation of CAR T and bystander immune cells, CRS is characterized by significant elevation of CAR T-cell-derived IFN- $\gamma$, and monocytederived IL-1 and IL-6 [55,56] (Figure 2b). Other cytokines, such as IL-2, IL-8, IL-10, IL-15, MCP-1, and TNF- $\alpha$ are also elevated [4]. Coagulopathy is frequently encountered in CAR T-cell therapy; laboratory findings of mild to moderate consumptive coagulopathy are common. In a study of 100 patients receiving anti-CD19 CAR T-cell therapy, 50\% had elevated D-dimer, $23 \%$ had decreased fibrinogen, $27 \%$ had prolonged PT or partial thromboplastin time (PTT), and seven (7\%) patients developed DIC [57]. Moreover, the study also found an increase in the incidence and severity of coagulopathy with higher grades of CRS, and DIC was exclusively seen in patients with severe CRS [57]. In another study of 53 patients, $30(56.6 \%)$ of them developed abnormal coagulation tests, manifesting as low fibrinogen, high D-dimer, and prolonged PT and PTT; 15 (28.3\%) patients met the criteria for DIC based on a modified scoring system [58]. Moreover, microvascular thrombosis has been universally identified in fatal cases due to severe CAR T-related toxicity [59]. A study by Hay et al. [4] shed light on the mechanistic link between CRS and coagulopathy in CAR T-cell therapy; they found that biomarkers of endothelial activation, such as angiotensin-1/2 and vWF multimers, were strongly associated with the CRS severity. Clinically, patients have an increased risk of thrombosis. For example, in a single center study of 148 patients, $11 \%$ developed new venous thromboembolism (VTE) between day 0 and 100 after CAR T-cell infusion, while none had major bleeding events [60].

\subsection{Coagulopathy in COVID-19}

COVID-19 is caused by the severe acute respiratory syndrome coronavirus 2 (SARS-CoV-2). Emerging in Wuhan, China, in late 2019 and subsequently spreading worldwide, the infection has a mortality rate as high as $30 \%$ in critically ill patients [61]. Since the early spread of COVID-19, high levels of cytokines have been identified in critically ill patients. The levels of IL-2R, IL-6, IL-10, and TNF- $\alpha$ were significantly higher in severe than in nonsevere cases or healthy controls [62-64]. In addition, the levels of IL-1, IL-4, IL-7, IL-8, IL-9, granulocyte colony stimulating factor (G-CSF), MCP-1, GM-CSF, and IFN- $\gamma$ were also mildly elevated in patients with COVID-19 compared with healthy controls [62]. However, the number of IFN- $\gamma$-expressing CD4+ T cells was significantly decreased in severe cases [63]; in addition, higher IL-6/ IFN- $\gamma$ ratio was associated with more severe diseases [65], indicating a relatively low IFN- $\gamma$ level in these cases. Furthermore, the severity of CRS is correlated with survival. In one study, patients who died from COVID-19 had significantly higher IL-6 levels than those who survived [66]. The mechanisms of CRS in COVID-19 are poorly understood. However, given the similarity between SARS-CoV-2 and SARS-CoV, the culprit of SARS, CRS could be due to direct infection and activation of monocytes, macrophages, and dendritic cells, through the angiotensin-converting enzyme 2 (ACE2) receptors on immune cells [67]. Another possible mechanism is activation of the complement system by viral infection, with resultant generation of $\mathrm{C} 5 \mathrm{a}$ anaphylatoxin, which can further activate neutrophils and monocytes to cause CRS [68] (Figure 2c).

Common laboratory findings include elevated D-dimer and fibrinogen level, minimally prolonged PT and aPTT, and mild thrombocytopenia; rarely do patients with severe COVID-19 progress to overt DIC [69]. The elevated fibrinogen level in COVID-19 is presumably due to an acute phase response, as Ranucci et al. [70] showed that the fibrinogen level was positively associated with the IL-6 level. Autopsy studies of decedents with COVID-19 found formation of platelet-rich microthrombi in multiple organs including lungs, coronary arteries, liver and kidneys [71]. It has been speculated that microvascular thrombosis associated with COVID-19 is not rare, especially in severe cases, however without the extent of consumptive coagulopathy observed in sepsis-related DIC [72]. For patients with COVID-19, signs of TMA, such as schistocytes and hemolytic anemia, are rarely seen [73]. However, subclinical microvascular thrombosis in these patients cannot not be excluded. Clinically, the risk of thrombosis is markedly elevated, but with high heterogeneity in different studies. For example, in China and Europe, the incidence of VTE in the intensive care unit (ICU) patients varies from $20 \%$ to $43 \%$ despite VTE prophylaxis [74-76]. In the United States, however, the rate of VTE in critically ill patients was only around 7\% [77]. In a meta-analysis of 86 studies, the overall VTE prevalence was $14.1 \%$, with $40.3 \%$ with universal ultrasound screening and $9.5 \%$ without screening; subgroup analysis revealed a VTE prevalence of $7.9 \%$ in the non-ICU population and $22.7 \%$ in ICU patients [78]. The far lower rate of diagnosed VTE in 
the United States could be due to occult thromboembolic events, as CT pulmonary angiograms and limb Doppler are not routinely performed unless the clinical suspicion is high [79].

\subsection{The Many Faces of CRS-related Coagulopathy}

Despite CRS being a key feature in all three scenarios and likely a crucial contributor to the coagulopathy, differences exist in laboratory findings and clinical manifestations (Table 1). However, one unifying feature is the development of microvascular thrombosis, although the severity varies among different scenarios. Primary HLH and CAR T-cell therapy are associated with more severe TMA with DIC, while COVID-19 is rarely associated with DIC. This is possibly related to the different severities of CRS. For example, the peak value of IFN- $\gamma$, a key proinflammatory cytokine in CRS, is significantly higher in HLH (median $901 \mathrm{pg} / \mathrm{mL}$ [35]) and CAR T $(1000 \mathrm{pg} / \mathrm{mL}$ [80]) than even in the most severe cases of COVID19 (10 pg/mL [62]). Another universally elevated cytokine in CRS, IL-6, was also higher in HLH (median peak $64 \mathrm{pg} / \mathrm{mL}$ [35]) and CAR T $(10,000 \mathrm{pg} / \mathrm{mL}[80])$ than severe cases of COVID-19 (40 $\mathrm{pg} / \mathrm{mL}[63])$.

Another noticeable difference is the CRS profile. HLH is characterized by markedly elevated IFN- $\gamma$ level; CAR T-cell therapy is known for significantly elevated IL-1 and IL-6 level; while COVID-19 has relatively low levels of both type I [81] and type II interferons [62]. It is generally believed that elevated proinflammatory cytokines are associated with a procoagulant state, as summarized above. However, little evidence exists as how different cytokines could lead to certain presentations of coagulopathy.

Finally, the underlying conditions associated with CRS may also explain the different presentations. Secondary HLH is often triggered by another severe systemic inflammatory condition, such as fulminant infection or cancer, which themselves are known causes of DIC. Moreover, platelets play a key role in preventing bleeding in inflammation, through mechanisms such as angiopoietin-1 mediated stabilization of endothelial cell-cell junction [82] and direct sealing of endothelial gaps by engaging platelet receptors [83]. Given that HLH and severe CRS are associated with more severe thrombocytopenia, the bleeding risk will be elevated. On the other hand, anti-CD19 CAR T cells are used in patients with relapsed/refractory B-cell malignancies, conditions associated with increased thrombotic risk. The preexisting risk of relapsed/refractory B-cell malignancies combined with CRS-related coagulopathy in CAR T-cell therapy likely contribute to a hypercoagulable state with increased incidence of VTE. As for COVID-19, there are several unique mechanisms on top of the CRS that could lead to further increased risk of thrombosis. First, SARS-CoV-2 can directly infect endothelial cells causing endotheliitis and leading to activation of the coagulation cascade [84]. Moreover, a unique phenomenon in sepsis-related coagulopathy called NETosis is also believed to play a major role $[85,86]$. Neutrophils, as part of the innate immune system, are activated upon pathogen exposure and can expulse their chromatin decorated with antimicrobial agents which can capture and kill pathogens - a process known as neutrophil extracellular traps (NETs) formation or NETosis [87]. Intravascular aggregation of NETs can lead to occlusion of affected vessels [85]. Moreover, NET itself is a strong activator of platelets, leading to aggregation and thrombosis [88].

\section{EFFICACY OF CYTOKINE REDUCTION IN THE MANAGEMENT OF COAGULOPATHY}

\subsection{Cytokine Inhibitors}

Monoclonal antibodies against cytokines or their respective receptors have achieved great success in controlling CRS. For example, in HLH where IFN- $\gamma$ plays the major role, use of the anti-IFN- $\gamma$ monoclonal antibody emapalumab has shown promising results in reducing the disease severity [89] and correcting coagulation abnormalities [90]. In addition to IFN- $\gamma$ inhibition, the effectiveness of IL-1 and IL- 6 inhibition in HLH are being actively studied [91,92]. In CAR T-cell therapy, the IL-6 receptor inhibitor tocilizumab has become the first-line treatment for CRS [93]. At the

Table 1 Epidemiology and presentations of coagulopathy in HLH, CAR T-cell therapy, and COVID-19

\begin{tabular}{|c|c|c|c|c|c|c|}
\hline & Incidence of CRS & $\begin{array}{l}\text { Incidence of } \\
\text { coagulopathy }\end{array}$ & Cytokine profile & $\begin{array}{l}\text { Laboratory } \\
\text { abnormalities }\end{array}$ & $\begin{array}{l}\text { Pathological } \\
\text { presentation }\end{array}$ & $\begin{array}{l}\text { Clinical } \\
\text { presentation }\end{array}$ \\
\hline HLH & Close to $100 \%$ & Close to $100 \%$ & $\begin{array}{l}\uparrow \uparrow \text { INF- } \gamma \\
\uparrow \text { IL-6, IL-10 }\end{array}$ & $\begin{array}{l}\uparrow \text { D-dimer, FDP, PT, } \\
\text { aPTT } \\
\downarrow \text { Fibrinogen, } \\
\text { platelets }\end{array}$ & $\begin{array}{l}\text { Consumptive } \\
\text { coagulopathy } \\
\text { Diffuse TMA } \\
\text { DIC common }\end{array}$ & Increased bleeding \\
\hline CAR T-cell therapy & Around 50\% & Around 50\% & $\begin{array}{l}\text { } \uparrow \text { IL-6, IL-1 } \\
\text { 个 INF- } \gamma \text {, IL-2, IL-8, } \\
\text { IL-10, IL-15, } \\
\text { MCP-1, TNF- } \alpha\end{array}$ & $\begin{array}{l}\uparrow \text { D-dimer, FDP, PT, } \\
\text { aPTT } \\
\downarrow \text { Fibrinogen, } \\
\text { platelets }\end{array}$ & $\begin{array}{l}\text { Consumptive } \\
\text { coagulopathy } \\
\text { TMA in severe } \\
\text { disease } \\
\text { DIC in severe } \\
\text { disease }\end{array}$ & Increased VTE \\
\hline COVID-19 & $\begin{array}{l}\text { Common in } \\
\text { severe cases }\end{array}$ & $\begin{array}{l}\text { Prevalence of VTE: } \\
\quad 14.1 \%\end{array}$ & $\begin{array}{l}\text { } \uparrow \text { IL-2R, IL-6, } \\
\text { IL-10, TNF- } \alpha \\
\text { 个 IL-1, IL-4, IL-7, } \\
\text { IL-8, IL-9, G(M)- } \\
\text { CSF, MCP-1 } \\
\leftrightarrow \text { INF- } \gamma\end{array}$ & $\begin{array}{l}\uparrow \text { D-dimer, FDP, } \\
\text { fibrinogen } \\
\leftrightarrow \text { Platelets, } \\
\text { PT, aPTT }\end{array}$ & $\begin{array}{l}\text { No consumptive } \\
\text { coagulopathy } \\
\text { Microvascular } \\
\text { thrombosis in } \\
\text { severe disease } \\
\text { DIC rare }\end{array}$ & Increased VTE \\
\hline
\end{tabular}


same time, coagulopathy could also be reversed with tocilizumab. For example, in a study of 15 patients who developed signs of DIC after receiving anti-CD19 CAR T-cell therapy and were treated with tocilizumab, 12 (80\%) were rescued from DIC within 7 days [58]. If tocilizumab and corticosteroids failed to achieve control of CRS, therapies such as the IL- 1 receptor inhibitor anakinra and the IL-6 inhibitor siltuximab can be attempted. Anakinra and siltuximab have extra benefit for mitigating central nervous system CRS, by crossing the blood-brain-barrier and directly blocking IL-6, respectively [94]. Their effects on reversing coagulopathy need to be confirmed.

The cytokine profile in COVID-19 is characterized by high levels of IL- 6 and TNF- $\alpha$, with relatively low IFN- $\gamma$. Tocilizumab has been trialed in COVID-19 to mitigate CRS. Although early retrospective studies showed some promising results [95,96], a randomized control trial did not find tocilizumab effective for preventing intubation or death in moderately ill patients [97]. Its effects on coagulopathy, however, remain to be established. Studies regarding other cytokine inhibitors, such as the IL-1 receptor inhibitor anakinra, IL-6 inhibitor siltuximab and anti-TNF antibody infliximab, are ongoing $[98,99]$. Although the evidence is limited, extrapolating the success in reversing coagulopathy in HLH and CAR T should be cautioned, as some unique thrombotic mechanisms in COVID-19, such as the endotheliitis and NETosis, would not be affected by cytokine inhibition.

\subsection{Other Therapies Targeting the Cytokine Pathway}

\subsubsection{Plasma exchange}

Plasma exchange is an extracorporeal blood purification technique that replaces the patient's plasma with another fluid such as allogenic plasma. It helps maintain hemostasis by removing excessive cytokines and correcting coagulation factors at the same time. It is the standard treatment for a subtype of TMA, thrombocytopenic purpura, through mechanisms of replenishing ADAMTS-13 and removing ADAMTS-13 inhibitors [100]. Plasma exchange has also been tried in DIC with some success [101,102]. While plasma exchange is not a standard therapy for CRS in HLH or CAR T-cell therapy, it has been successfully applied in both scenarios [103,104]. Plasma exchange has also been entertained in COVID-19 and halted disease progression was reported [105]. More evidence is needed to establish the benefit of plasma exchange in CRS-related coagulopathy, especially in patients with severe disease. However, routine use of plasma exchange would not be feasible, due to the requirement for central venous access, specific equipment, and high cost.

\subsubsection{JAK inhibitors}

Janus kinases (JAK) are the primary downstream signaling pathway of many proinflammatory cytokines such as IL- 6 and IFN- $\gamma$, with noticeable exceptions such as IL- 1 and TNF- $\alpha$ [106]. The JAK inhibitors ruxolitinib, baricitinib and tofacitinib have been successfully applied to treat CRS. In a pilot trial of five patients with secondary HLH treated with ruxolitinib, all patients achieved response [107]. The efficacy of JAK inhibition in controlling CRS in CAR T-cell therapy has been proven in a preclinical model [108]. The efficacy of baricitinib in COVID-19 is being actively tested in the Adaptive COVID-19 Treatment Trial 2 (ACTT-2) trial. Of note, JAK inhibitors have the advantage over cytokine inhibitors due to their oral administration and capacity to inhibit multiple cytokine pathways at the same time. Moreover, in COVID-19, JAK inhibitors have additional anti-viral effects by blocking SARS-CoV-2 entry [109]. However, there has been concern over an increased thromboembolism risk associated with JAK inhibitors in rheumatoid arthritis, based on data from post-marketing surveillance databases, although the events are too few to be certain [110]. Therefore, the effects of JAK inhibitors on cytokine-related coagulopathy need to be carefully studied.

\subsubsection{Complement system blockade}

The complement system is an innate immune system activated by pathogens such as the SARS-CoV-2. Its activation can directly lead to thrombosis due to endothelial damage. Moreover, complement activation could be upstream of CRS in COVID-19 [68]. Therefore, the use of anti-C5 antibody eculizumab is being tested; preliminary results showed a decrease in cytokine levels [111]. However, its application in the non-COVID-19 setting will likely be limited, due to lack of complement activation in other scenarios.

\subsubsection{Corticosteroids}

Corticosteroids remain as one of the first-line therapies for HLH. In CAR T-cell therapy, corticosteroids are usually reserved as the last resort for life-threatening CRS, due to concerns of CAR T-cell suppression. The use of corticosteroids in COVID-19 was initially discouraged due to worse outcomes when used in SARS and MERS [112]. However, a prospective study found that hospitalized patients had improved survival when dexamethasone was used [113], likely due to more severe CRS in COVID-19 than SARS and MERS. Corticosteroids have become the standard treatment for patients with COVID-19 requiring supplemental oxygen. The effects of corticosteroids on coagulopathy need to be studied in the future.

\subsubsection{Bruton's tyrosine kinase inhibitor}

The Bruton's tyrosine kinase inhibitor ibrutinib has been shown to also inhibit the IL-2-induced tyrosine kinase, resulting in reduction of cytokine production [114]. In a mouse model, ibrutinib reduced the severity of CRS mediated by CAR T-cell therapy [115]. In a retrospective study of patients with relapsed or refractory chronic lymphocytic leukemia receiving CAR T-cell therapy with or without ibrutinib, the use of ibrutinib was associated with lower CRS severity [116].

\section{CONCLUDING REMARKS}

In summary, there has been ample evidence to support a direct and causative association between proinflammatory cytokines and coagulopathy. Although the cytokine profile and presentations of coagulopathy differ in the various causes of CRS, similar management methods could be applied. The story behind CRS is an excellent example of how the progress of medical knowledge 
in one field can facilitate understandings in other fields. If it were not for the extensive research on sepsis-related coagulopathy and CAR T-related CRS, it would be inconceivable to quickly recognize the important crosstalk between cytokine and coagulopathy in COVID-19. Despite broad application of cytokine inhibitors, further studies are needed to confirm their efficacy in reversing coagulopathy.

\section{CONFLICTS OF INTEREST}

The authors declare they have no conflicts of interest.

\section{AUTHORS' CONTRIBUTION}

JW and JD wrote the manuscript. JW designed the figures.

\section{FUNDING}

No financial support was provided.

\section{REFERENCES}

[1] Chatenoud L, Ferran C, Reuter A, Legendre C, Gevaert Y, Kreis H, et al. Systemic reaction to the anti-T-cell monoclonal antibody OKT3 in relation to serum levels of tumor necrosis factor and interferon-gamma [corrected]. N Engl J Med 1989;320;1420-1.

[2] Moore JB, June CH. Cytokine release syndrome in severe COVID-19. Science 2020;368;473-4.

[3] Blair P, Rex S, Vitseva O, Beaulieu L, Tanriverdi K, Chakrabarti S, et al. Stimulation of toll-like receptor 2 in human platelets induces a thromboinflammatory response through activation of phosphoinositide 3-kinase. Circ Res 2009;104;346-54.

[4] Hay KA, Hanafi LA, Li D, Gust J, Conrad Liles W, Wurfel MM, et al. Kinetics and biomarkers of severe cytokine release syndrome after CD19 chimeric antigen receptor-modified T-cell therapy. Blood 2017;130;2295-306.

[5] van Hinsbergh VWM. Endothelium - role in regulation of coagulation and inflammation. Semin Immunopathol 2012;34;93-106.

[6] Bombeli T, Karsan A, Tait JF, Harlan JM. Apoptotic vascular endothelial cells become procoagulant. Blood 1997;89;2429-42.

[7] Pober JS, Sessa WC. Evolving functions of endothelial cells in inflammation. Nat Rev Immunol 2007;7;803-15.

[8] Giddings JC, Shall L. Enhanced release of von Willebrand factor by human endothelial cells in culture in the presence of phorbol myristate acetate and interleukin 1. Thromb Res 1987;47;259-67.

[9] Paleolog EM, Crossman DC, McVey JH, Pearson JD. Differential regulation by cytokines of constitutive and stimulated secretion of von Willebrand factor from endothelial cells. Blood 1990;75; 688-95.

[10] Bernardo A, Ball C, Nolasco L, Moake JF, Dong JF. Effects of inflammatory cytokines on the release and cleavage of the endothelial cell-derived ultralarge von Willebrand factor multimers under flow. Blood 2004;104;100-6.

[11] Petrache I, Birukova A, Ramirez SI, Garcia JG, Verin AD. The role of the microtubules in tumor necrosis factor-alpha-induced endothelial cell permeability. Am J Respir Cell Mol Biol 2003;28; 574-81.
[12] Wang S, Le TQ, Kurihara N, Chida J, Cisse Y, Yano M, et al. Influenza virus-cytokine-protease cycle in the pathogenesis of vascular hyperpermeability in severe influenza. J Infect Dis 2010;202;991-1001.

[13] Danese S, Vetrano S, Zhang L, Poplis VA, Castellino FJ. The protein $\mathrm{C}$ pathway in tissue inflammation and injury: pathogenic role and therapeutic implications. Blood 2010;115;1121-30.

[14] Cao WJ, Niiya M, Zheng XW, Shang DZ, Zheng XL. Inflammatory cytokines inhibit ADAMTS13 synthesis in hepatic stellate cells and endothelial cells. J Thromb Haemost 2008;6;1233-5.

[15] Ishibashi T, Kimura H, Uchida T, Kariyone S, Friese P, Burstein SA. Human interleukin 6 is a direct promoter of maturation of megakaryocytes in vitro. Proc Natl Acad Sci U S A 1989;86;5953-7.

[16] Nagler A, Deutsch VR, Varadi G, Pick M, Eldor A, Slavin S. Recombinant human interleukin-6 accelerates in-vitro megakaryocytopoiesis and platelet recovery post autologous peripheral blood stem cell transplantation. Leuk Lymphoma 1995;19;343-9.

[17] Nishimura S, Nagasaki M, Kunishima S, Sawaguchi A, Sakata A, Sakaguchi H, et al. IL-1alpha induces thrombopoiesis through megakaryocyte rupture in response to acute platelet needs. J Cell Biol 2015;209;453-66.

[18] Behrens K, Alexander WS. Cytokine control of megakaryopoiesis. Growth Factors 2018;36;89-103.

[19] Golebiewska EM, Poole AW. Platelet secretion: from haemostasis to wound healing and beyond. Blood Rev 2015;29;153-62.

[20] Todoroki N, Watanabe Y, Akaike T, Katagiri Y, Tanoue K, Yamazaki $\mathrm{H}$, et al. Enhancement by IL-1 beta and IFN-gamma of platelet activation: adhesion to leukocytes via GMP-140/ PADGEM protein (CD62). Biochem Biophys Res Commun 1991;179;756-61.

[21] Oleksowicz L, Paciucci PA, Zuckerman D, Colorito A, Rand JH, Holland JF. Alterations of platelet function induced by interleukin-2. J Immunother 1991;10;363-70.

[22] Li N. Platelet-lymphocyte cross-talk. J Leukoc Biol 2008;83;1069-78.

[23] Szotowski B, Antoniak S, Poller W, Schultheiss HP, Rauch U. Procoagulant soluble tissue factor is released from endothelial cells in response to inflammatory cytokines. Circ Res 2005;96; 1233-9.

[24] Khan MM, Liu Y, Khan ME, Gilman ML, Khan ST, Bromberg M, et al. Upregulation of tissue factor in monocytes by cleaved high molecular weight kininogen is dependent on TNF-alpha and IL-1beta. Am J Physiol Heart Circ Physiol 2010;298;H652-H8.

[25] Witkowski M, Landmesser U, Rauch U. Tissue factor as a link between inflammation and coagulation. Trends Cardiovasc Med 2016;26;297-303.

[26] van der Poll T, Büller HR, ten Cate H, Wortel CH, Bauer KA, van Deventer SJH, et al. Activation of coagulation after administration of tumor necrosis factor to normal subjects. N Engl J Med 1990;322;1622-7.

[27] Lentz SR, Tsiang M, Sadler JE. Regulation of thrombomodulin by tumor necrosis factor-alpha: comparison of transcriptional and posttranscriptional mechanisms. Blood 1991;77;542-50.

[28] Xu J, Qu D, Esmon NL, Esmon CT. Metalloproteolytic release of endothelial cell protein C receptor. J Biol Chem 2000;275;6038-44.

[29] Gallicchio M, Hufnagl P, Wojta J, Tipping P. IFN-gamma inhibits thrombin- and endotoxin-induced plasminogen activator inhibitor type 1 in human endothelial cells. J Immunol 1996;157;2610-17.

[30] Schleef RR, Bevilacqua MP, Sawdey M, Gimbrone MA, Loskutoff DJ. Cytokine activation of vascular endothelium. Effects on tissuetype plasminogen activator and type 1 plasminogen activator inhibitor. J Biol Chem 1988;263;5797-803. 
[31] Knipe L, Meli A, Hewlett L, Bierings R, Dempster J, Skehel P, et al. A revised model for the secretion of tPA and cytokines from cultured endothelial cells. Blood 2010;116;2183-91.

[32] van Hinsbergh VW, van den Berg EA, Fiers W, Dooijewaard G. Tumor necrosis factor induces the production of urokinase-type plasminogen activator by human endothelial cells. Blood 1990; $75 ; 1991-8$.

[33] Pajkrt D, van der Poll T, Levi M, Cutler DL, Affrime MB, van den Ende A, et al. Interleukin-10 inhibits activation of coagulation and fibrinolysis during human endotoxemia. Blood 1997;89;2701-5.

[34] van der Poll T, Levi M, Büller HR, van Deventer SJ, de Boer JP, Hack CE, et al. Fibrinolytic response to tumor necrosis factor in healthy subjects. J Exp Med 1991;174;729-32.

[35] Tang Y, Xu X, Song H, Yang S, Shi S, Wei J, et al. Early diagnostic and prognostic significance of a specific Th1/Th2 cytokine pattern in children with haemophagocytic syndrome. Br J Haematol 2008;143;84-91.

[36] Teachey DT, Rheingold SR, Maude SL, Zugmaier G, Barrett DM, Seif AE, et al. Cytokine release syndrome after blinatumomab treatment related to abnormal macrophage activation and ameliorated with cytokine-directed therapy. Blood 2013;121; 5154-7.

[37] Frey N, Porter D. Cytokine release syndrome with chimeric antigen receptor $\mathrm{T}$ cell therapy. Biol Blood Marrow Transplant 2019;25;e123-e7.

[38] Abboud R, Keller J, Slade M, DiPersio JF, Westervelt P, Rettig MP, et al. Severe cytokine-release syndrome after T cell-replete peripheral blood haploidentical donor transplantation is associated with poor survival and anti-IL-6 therapy is safe and well tolerated. Biol Blood Marrow Transplant 2016;22;1851-60.

[39] Imus PH, Blackford AL, Bettinotti M, Luznik L, Fuchs EJ, Huff $\mathrm{CA}$, et al. Severe cytokine release syndrome after haploidentical peripheral blood stem cell transplantation. Biol Blood Marrow Transplant 2019;25;2431-7.

[40] Huang KJ, Su IJ, Theron M, Wu YC, Lai SK, Liu CC, et al. An interferon-gamma-related cytokine storm in SARS patients. J Med Virol 2005;75;185-94.

[41] Mahallawi WH, Khabour OF, Zhang Q, Makhdoum HM, Suliman BA. MERS-CoV infection in humans is associated with a pro-inflammatory Th1 and Th17 cytokine profile. Cytokine $2018 ; 104 ; 8-13$.

[42] Sieni E, Cetica V, Hackmann Y, Coniglio ML, Da Ros M, Ciambotti B, et al. Familial hemophagocytic lymphohistiocytosis: when rare diseases shed light on immune system functioning. Front Immunol 2014;5;167.

[43] Maude SL, Barrett D, Teachey DT, Grupp SA. Managing cytokine release syndrome associated with novel T cell-engaging therapies. Cancer J 2014;20;119-22.

[44] Teachey DT, Lacey SF, Shaw PA, Melenhorst JJ, Maude SL, Frey N, et al. Identification of predictive biomarkers for cytokine release syndrome after chimeric antigen receptor T-cell therapy for acute lymphoblastic leukemia. Cancer Discov 2016;6;664-79.

[45] Weiss ES, Girard-Guyonvarc'h C, Holzinger D, de Jesus AA, Tariq Z, Picarsic J, et al. Interleukin-18 diagnostically distinguishes and pathogenically promotes human and murine macrophage activation syndrome. Blood 2018;131;1442-55.

[46] Henter JI, Elinder G, Söder O, Hansson M, Andersson B, Andersson U. Hypercytokinemia in familial hemophagocytic lymphohistiocytosis. Blood 1991;78;2918-22.
[47] Chen Y, Wang Z, Luo Z, Zhao N, Yang S, Tang Y. Comparison of Th1/Th2 cytokine profiles between primary and secondary haemophagocytic lymphohistiocytosis. Ital J Pediatr 2016;42;50.

[48] Prencipe G, Caiello I, Pascarella A, Grom AA, Bracaglia C, Chatel L, et al. Neutralization of IFN-gamma reverts clinical and laboratory features in a mouse model of macrophage activation syndrome. J Allergy Clin Immunol 2018;141;1439-49.

[49] Valade S, Azoulay E, Galicier L, Boutboul D, Zafrani L, Stepanian A, et al. Coagulation disorders and bleedings in critically ill patients with hemophagocytic lymphohistiocytosis. Medicine (Baltimore) 2015;94;e1692.

[50] Gloude NJ, Dandoy CE, Davies SM, Myers KC, Jordan MB, Marsh R, et al. Thinking beyond HLH: clinical features of patients with concurrent presentation of hemophagocytic lymphohistiocytosis and thrombotic microangiopathy. Biol Blood Marrow Transplant 2020;26;S15-S16.

[51] La Rosee P, Horne A, Hines M, von Bahr Greenwood T, Machowicz R, Berliner N, et al. Recommendations for the management of hemophagocytic lymphohistiocytosis in adults. Blood 2019;133;2465-77.

[52] Wang J, Hu Y, Huang H. Current development of chimeric antigen receptor T-cell therapy. Stem Cell Investig 2018;5;44.

[53] Cao JX, Wang H, Gao WJ, You J, Wu LH, Wang ZX. The incidence of cytokine release syndrome and neurotoxicity of CD19 chimeric antigen receptor- $\mathrm{T}$ cell therapy in the patient with acute lymphoblastic leukemia and lymphoma. Cytotherapy 2020;22;214-26.

[54] Al-Mansour M, Al-Foheidi M, Ibrahim E. Efficacy and safety of second-generation CAR T-cell therapy in diffuse large B-cell lymphoma: a meta-analysis. Mol Clin Oncol 2020;13;33.

[55] Giavridis T, van der Stegen SJC, Eyquem J, Hamieh M, Piersigilli A, Sadelain M. CAR T cell-induced cytokine release syndrome is mediated by macrophages and abated by IL- 1 blockade. Nat Med 2018;24;731-8.

[56] Norelli M, Camisa B, Barbiera G, Falcone L, Purevdorj A, Genua M, et al. Monocyte-derived IL-1 and IL-6 are differentially required for cytokine-release syndrome and neurotoxicity due to CAR T cells. Nat Med 2018;24;739-48.

[57] Wang Y, Qi K, Cheng H, Cao J, Shi M, Qiao J, et al. Coagulation disorders after chimeric antigen receptor T cell therapy: analysis of 100 patients with relapsed and refractory hematologic malignancies. Biol Blood Marrow Transplant 2020;26;865-75.

[58] Jiang H, Liu L, Guo T, Wu Y, Ai L, Deng J, et al. Improving the safety of CAR-T cell therapy by controlling CRS-related coagulopathy. Ann Hematol 2019;98;1721-32.

[59] Gust J, Hay KA, Hanafi LA, Li D, Myerson D, Gonzalez-Cuyar LF, et al. Endothelial activation and blood-brain barrier disruption in neurotoxicity after adoptive immunotherapy with CD19 CAR-T cells. Cancer Discov 2017;7;1404-19.

[60] Hashmi H, Mirza AS, Darwin A, Logothetis C, Garcia F, Kommalapati A, et al. Venous thromboembolism associated with CD19-directed CAR T-cell therapy in large B-cell lymphoma. Blood Adv 2020;4;4086-90.

[61] Auld SC, Caridi-Scheible M, Blum JM, Robichaux C, Kraft C, Jacob JT, et al. ICU and ventilator mortality among critically ill adults with coronavirus disease 2019. Crit Care Med 2020;48;e799-e804.

[62] Huang C, Wang Y, Li X, Ren L, Zhao J, Hu Y, et al. Clinical features of patients infected with 2019 novel coronavirus in Wuhan, China. Lancet 2020;395;497-506. 
[63] Chen G, Wu D, Guo W, Cao Y, Huang D, Wang H, et al. Clinical and immunological features of severe and moderate coronavirus disease 2019. J Clin Invest 2020;130;2620-9.

[64] Hou H, Zhang B, Huang H, Luo Y, Wu S, Tang G, et al. Using IL-2R/lymphocytes for predicting the clinical progression of patients with COVID-19. Clin Exp Immunol 2020;201;76-84.

[65] Lagunas-Rangel FA, Chavez-Valencia V. High IL-6/IFN- $\gamma$ ratio could be associated with severe disease in COVID-19 patients. J Med Virol 2020;92;1789-90.

[66] Ruan Q, Yang K, Wang W, Jiang L, Song J. Clinical predictors of mortality due to COVID-19 based on an analysis of data of 150 patients from Wuhan, China. Intensive Care Med 2020;46;846-8.

[67] Law HK, Cheung CY, Ng HY, Sia SF, Chan YO, Luk W, et al. Chemokine up-regulation in SARS-coronavirus-infected, monocyte-derived human dendritic cells. Blood 2005;106;2366-74.

[68] Song WC, FitzGerald GA. COVID-19, microangiopathy, hemostatic activation, and complement. J Clin Invest 2020;130;3950-3.

[69] Levi M, Thachil J, Iba T, Levy JH. Coagulation abnormalities and thrombosis in patients with COVID-19. Lancet Haematol 2020;7;e438-e40.

[70] Ranucci M, Ballotta A, Di Dedda U, Bayshnikova E, Dei Poli M, Resta M, et al. The procoagulant pattern of patients with COVID19 acute respiratory distress syndrome. J Thromb Haemost 2020;18;1747-51.

[71] Rapkiewicz AV, Mai X, Carsons SE, Pittaluga S, Kleiner DE, Berger JS, et al. Megakaryocytes and platelet-fibrin thrombi characterize multi-organ thrombosis at autopsy in COVID-19: a case series. EClinicalMedicine 2020;24;100434.

[72] Merrill JT, Erkan D, Winakur J, James JA. Emerging evidence of a COVID-19 thrombotic syndrome has treatment implications. Nat Rev Rheumatol 2020;16;581-9.

[73] Becker RC. COVID-19 update: Covid-19-associated coagulopathy. J Thromb Thrombolysis 2020;50;54-67.

[74] Middeldorp S, Coppens M, van Haaps TF, Foppen M, Vlaar AP, Müller MCA, et al. Incidence of venous thromboembolism in hospitalized patients with COVID-19. J Thromb Haemost 2020;18; 1995-2002.

[75] Klok FA, Kruip MJHA, van der Meer NJM, Arbous MS, Gommers DAMPJ, Kant KM, et al. Incidence of thrombotic complications in critically ill ICU patients with COVID-19. Thromb Res 2020;191;145-7.

[76] Helms J, Tacquard C, Severac F, Leonard-Lorant I, Ohana M, Delabranche X, et al. High risk of thrombosis in patients with severe SARS-CoV-2 infection: a multicenter prospective cohort study. Intensive Care Med 2020;46;1089-98.

[77] Goyal P, Choi JJ, Pinheiro LC, Schenck EJ, Chen R, Jabri A, et al. Clinical characteristics of Covid-19 in New York City. N Engl J Med 2020;382;2372-4.

[78] Nopp S, Moik F, Jilma B, Pabinger I, Ay C. Risk of venous thromboembolism in patients with COVID-19: a systematic review and meta-analysis. Res Pract Thromb Haemost 2020;4; 1178-91.

[79] Al-Samkari H, Karp Leaf RS, Dzik WH, Carlson JCT, Fogerty AE, Waheed A, et al. COVID-19 and coagulation: bleeding and thrombotic manifestations of SARS-CoV-2 infection. Blood 2020;136;489-500.

[80] Maude SL, Frey N, Shaw PA, Aplenc R, Barrett DM, Bunin NJ, et al. Chimeric antigen receptor $\mathrm{T}$ cells for sustained remissions in leukemia. N Engl J Med 2014;371;1507-17.
[81] Hadjadj J, Yatim N, Barnabei L, Corneau A, Boussier J, Smith N, et al. Impaired type I interferon activity and inflammatory responses in severe COVID-19 patients. Science 2020;369;718-24.

[82] Thurston G, Rudge JS, Ioffe E, Zhou H, Ross L, Croll SD, et al. Angiopoietin-1 protects the adult vasculature against plasma leakage. Nat Med 2000;6;460-3.

[83] Ho-Tin-Noé B, Demers M, Wagner DD. How platelets safeguard vascular integrity. J Thromb Haemost 2011;9;56-65.

[84] Varga Z, Flammer AJ, Steiger P, Haberecker M, Andermatt R, Zinkernagel AS, et al. Endothelial cell infection and endotheliitis in COVID-19. Lancet 2020;395;1417-18.

[85] Leppkes M, Knopf J, Naschberger E, Lindemann A, Singh J, Herrmann I, et al. Vascular occlusion by neutrophil extracellular traps in COVID-19. EBioMedicine 2020;58;102925.

[86] Nicolai L, Leunig A, Brambs S, Kaiser R, Weinberger T, Weigand M, et al. Immunothrombotic dysregulation in COVID-19 pneumonia is associated with respiratory failure and coagulopathy. Circulation 2020;142;1176-89.

[87] de Bont CM, Boelens WC, Pruijn GJM. NETosis, complement, and coagulation: a triangular relationship. Cell Mol Immunol 2019;16;19-27.

[88] Zucoloto AZ, Jenne CN. Platelet-neutrophil interplay: insights into neutrophil extracellular trap (NET)-driven coagulation in infection. Front Cardiovasc Med 2019;6;85.

[89] Locatelli F, Jordan MB, Allen C, Cesaro S, Rizzari C, Rao A, et al. Emapalumab in children with primary hemophagocytic lymphohistiocytosis. N Engl J Med 2020;382;1811-22.

[90] Lounder DT, Bin Q, de Min C, Jordan MB. Treatment of refractory hemophagocytic lymphohistiocytosis with emapalumab despite severe concurrent infections. Blood Adv 2019;3;47-50.

[91] Mehta P, Cron RQ, Hartwell J, Manson JJ, Tattersall RS. Silencing the cytokine storm: the use of intravenous anakinra in haemophagocytic lymphohistiocytosis or macrophage activation syndrome. Lancet Rheumatol 2020;2;e358-e67.

[92] Dufranc E, Del Bello A, Belliere J, Kamar N, Faguer S, TAIDI (Toulouse Acquired Immune Deficiency and Infection) study group. IL6-R blocking with tocilizumab in critically ill patients with hemophagocytic syndrome. Crit Care 2020;24;166.

[93] Mahmoudjafari Z, Hawks KG, Hsieh AA, Plesca D, Gatwood KS, Culos KA. American society for blood and marrow transplantation pharmacy special interest group survey on chimeric antigen receptor $\mathrm{T}$ cell therapy administrative, logistic, and toxicity management practices in the United States. Biol Blood Marrow Transplant 2019;25;26-33.

[94] Hunter BD, Jacobson CA. CART-cell associated neurotoxicity: mechanisms, clinicopathologic correlates, and future directions. J Natl Cancer Inst 2019;111;646-54.

[95] Guaraldi G, Meschiari M, Cozzi-Lepri A, Milic J, Tonelli R, Menozzi M, et al. Tocilizumab in patients with severe COVID-19: a retrospective cohort study. Lancet Rheumatol 2020;2;e474-e84.

[96] Kewan T, Covut F, Al-Jaghbeer MJ, Rose L, Gopalakrishna KV, Akbik B. Tocilizumab for treatment of patients with severe COVID-19: a retrospective cohort study. EClinicalMedicine 2020;24;100418.

[97] Stone JH, Frigault MJ, Serling-Boyd NJ, Fernandes AD, Harvey L, Foulkes AS, et al. Efficacy of tocilizumab in patients hospitalized with Covid-19. N Engl J Med 2020;383;2333-44.

[98] Huet T, Beaussier H, Voisin O, Jouveshomme S, Dauriat G, Lazareth I, et al. Anakinra for severe forms of COVID-19: a cohort study. Lancet Rheumatol 2020;2;e393-e400. 
[99] Stallmach A, Kortgen A, Gonnert F, Coldewey SM, Reuken P, Bauer M. Infliximab against severe COVID-19-induced cytokine storm syndrome with organ failure-a cautionary case series. Crit Care 2020;24;444.

[100] Moake JL. Thrombotic microangiopathies. N Engl J Med 2002;347;589-600.

[101] Churchwell KB, McManus ML, Kent P, Gorlin J, Galacki D, Humphreys D, et al. Intensive blood and plasma exchange for treatment of coagulopathy in meningococcemia. J Clin Apher $1995 ; 10 ; 171-7$.

[102] Stegmayr BG, Banga R, Berggren L, Norda R, Rydvall A, Vikerfors T. Plasma exchange as rescue therapy in multiple organ failure including acute renal failure. Crit Care Med $2003 ; 31 ; 1730-6$

[103] Xiao X, He X, Li Q, Zhang H, Meng J, Jiang Y, et al. Plasma exchange can be an alternative therapeutic modality for severe cytokine release syndrome after chimeric antigen receptor-T cell infusion: a case report. Clin Cancer Res 2019;25;29-34.

[104] Bosnak M, Erdogan S, Habibe Aktekin E, Bay A. Therapeutic plasma exchange in primary hemophagocytic lymphohistiocytosis: reports of two cases and a review of the literature. Transfus Apher Sci 2016;55;353-6.

[105] Shi H, Zhou C, He P, Huang S, Duan Y, Wang X, et al. Successful treatment with plasma exchange followed by intravenous immunogloblin in a critically ill patient with COVID-19. Int J Antimicrob Agents 2020;56;105974.

[106] Schwartz DM, Kanno Y, Villarino A, Ward M, Gadina M, O'Shea JJ. JAK inhibition as a therapeutic strategy for immune and inflammatory diseases. Nat Rev Drug Discov 2017;17;78.

[107] Ahmed A, Merrill SA, Alsawah F, Bockenstedt P, Campagnaro E, Devata S, et al. Ruxolitinib in adult patients with secondary haemophagocytic lymphohistiocytosis: an open-label, singlecentre, pilot trial. Lancet Haematol 2019;6;e630-e7.
[108] Kenderian SS, Ruella M, Shestova O, Kim MY, Klichinsky M, Chen F, et al. Ruxolitinib prevents cytokine release syndrome after CART cell therapy without impairing the anti-tumor effect in a xenograft model. Blood 2016;128;652.

[109] Richardson P, Griffin I, Tucker C, Smith D, Oechsle O, Phelan A, et al. Baricitinib as potential treatment for 2019-nCoV acute respiratory disease. Lancet 2020;395; e30-e1.

[110] Scott IC, Hider SL, Scott DL. Thromboembolism with janus kinase (JAK) inhibitors for rheumatoid arthritis: how real is the risk? Drug Saf 2018;41;645-53.

[111] Diurno F, Numis FG, Porta G, Cirillo F, Maddaluno S, Ragozzino A, et al. Eculizumab treatment in patients with COVID-19: preliminary results from real life ASL Napoli 2 Nord experience. Eur Rev Med Pharmacol Sci 2020;24;4040-7.

[112] Russell CD, Millar JE, Kenneth Baillie J. Clinical evidence does not support corticosteroid treatment for 2019-nCoV lung injury. Lancet 2020;395;473-5.

[113] RECOVERY Collaborative Group, Horby P, Lim WS, Emberson JR, Mafham M, Bell JL, et al. Dexamethasone in hospitalized patients with Covid-19 - preliminary report. N Engl J Med 2020;NEJMoa2021436.

[114] Kohrt HE, Sagiv-Barfi I, Rafiq S, Herman SEM, Butchar JP, Cheney C, et al. Ibrutinib antagonizes rituximab-dependent NK cell-mediated cytotoxicity. Blood 2014;123;1957-60.

[115] Ruella M, Kenderian SS, Shestova O, Klichinsky M, Melenhorst JJ, Wasik MA, et al. Kinase inhibitor ibrutinib to prevent cytokine-release syndrome after anti-CD19 chimeric antigen receptor $\mathrm{T}$ cells for B-cell neoplasms. Leukemia $2017 ; 31 ; 246-8$.

[116] Gauthier J, Hirayama AV, Purushe J, Hay KA, Lymp J, Li DH, et al. Feasibility and efficacy of CD19-targeted CAR T cells with concurrent ibrutinib for CLL after ibrutinib failure. Blood 2020;135;1650-60. 